\title{
Predictors of Response to (Etanercept) in the Treatment of Iraqi Patients with Active Rheumatoid Arthritis
}

\author{
Nizar A. Jassim* \\ FICMS (Intern. Med.), FICMS (Rheum. \& Med. Rehab)
}

Abstract:

Background: Since the introduction of tumour necrosis factor-alpha (TNF- $\alpha$ ) inhibitors including etanercept, their efficacy and safety in treatment of rheumatoid arthritis (RA) have been studied in many randomized controlled clinical trials. However, data regarding predictors of clinical response to anti-TNF therapy are still sparse.

Objective: To assess the predictors of response to etanercept in treatment of Iraqi patients with active RA. Methods: An open label single group prospective study was conducted over 15 months on 190 Iraqi patients with RA. All the included patients were given etanercept at a dose of $50 \mathrm{mg}$ by subcutaneous injection on a weeklybases. Each patient was followed at regular intervals of baseline, 1, 3 and 6 months for disease activity using Disease Activity Score 28 (DAS28). Also we assess six different patients characteristics (age, gender, disease duration, the presence of rheumatoid factor, smoking status and the concomitant use of methotrexate) as predictors to etanercept response.

Results: Data analysis showed a significant improvement in DAS28 with etanercept use over a period of 6 months. Females were more respondent to treatment than males. The concomitant use of methotrexate showed highly significant correlation with the treatment response. The other variables had no significant effect on response to treatment.

Conclusion: Female gender and concomitant use of methotrexate have a significant correlation with response to etanercept treatment.

Key words: Rheumatoid arthritis, etanercept, predictors of response, methotrxate.

Introduction:

Rheumatoid arthritis (RA) is a chronic systemic autoimmune inflammatory disease, which primarily affects the joints and is characterized by inflammation of synovial joints in a symmetrical pattern. Active disease is characterized by pain, swelling and stiffness of joints in combination with raised levels of inflammatory markers(1).

Alongside an improved understanding of the immune mechanisms involved in the pathogenesis of RA, a new class of drugs has been developed since the early 1990s. These so-called 'biologics' have been designed specifically at targeting and antagonizing key cytokines, thereby suppressing inflammation and preventing cartilage and bone destruction. At present, drugs that inhibit tumour necrosis factor-alpha (TNF- $\alpha$ ) are the most successful competitors of this new class of drugs in the treatment of RA. TNF- $\alpha$ blocking agents can be divided into soluble TNF- $\alpha$ receptors and antibodies against TNF- $\alpha$. Etanercept (soluble TNF- $\alpha$ receptor), was approved for RA treatment(2) .

The guidelines for use of anti-TNF in Iraq state that the TNF- $\alpha$ inhibitors are indicated for adults with RA should they have severe disease, assessed by disease activity score 28 (DAS28) and they have been treated with two disease-modifying antirheumatic drugs (DMARDs), including methotrexate, unless contraindicated(3).

*Dept. of Medicine, College of Medicine, University of Baghdad. Nazarlateef@yahoo.com
Since the introduction of TNF- $\alpha$ blocking agents, their efficacy and safety have been studied in many randomized controlled clinical trials(4) as well as observational studies of RA patients(5). However, data regarding predictors of good clinical response of anti-TNF therapy are still sparse. The aim of this study is to assess the predictors of response to etanercept in treatment of Iraqi patients with active RA.

\section{Patients and methods}

Study design: This is an open label single group prospective study that was conducted over 15 months period.

Patients: The study was conducted on Iraqi patients with RA who visited the Rheumatology Clinic in Baghdad Teaching Hospital from May 2012 to July 2013.

To be included in this study, the patient should meet the 1987 American College of Rheumatology criteria for the classification of RA(6), also he should have history of failed adequate response to conventional DMARDs and his disease activity score 28 (DAS28)(7) should be equal to or greater than 5.1 (severe disease activity).

The exclusion criteria include patients less than 18 years old, patients with a previous history of biologic agent intake and those with other connective tissue diseases overlapping with RA.

During the study period, 272 patients with RA were identified. However, only 195 patients met the inclusion/ exclusion criteria and 5 of those were lost during the follow up leaving a 
total of 190 patients who successfully completed the study.

Ethical issue and official permission: The study was granted ethical approval from the local ethics committee and a verbal consent was taken from every participant prior to involvement in the study after explaining the purpose of the study and ensuring privacy of the data.

Methods: All the included patients were given etanercept (Pfizer, USA) at a dose of $50 \mathrm{mg}$ by subcutaneous injection by a trained nurse on weekly bases for 6 months.

For each patient, a baseline data were collected during the first visit and all the participants were followed for six months, during which each patient was seen at regular intervals of 1 month, 3 months and 6 months. During these subsequent visits, further data were taken. The collected data include demographic data of patients regarding their age and sex and smoking status. These data were collected at the first visit. Medical data including the disease duration, previous and current RA medications (DMARDs, corticosteroids and biologics).These data were also collected during the first visit. Rheumatoid factor (RF) was performed at the first visit and other laboratory data including hemoglobin level, white blood cell count, aspartate aminotransferase, alanine aminotransferase, urea and creatinine levels were performed at the baseline and every subsequent visit. Assessment of disease activity by using DAS28 was performed during the baseline and every subsequent visit.

Statistical analysis: The data of the 190 patients in this study were entered into and analyzed by the statistical package for social science (SPSS) software version 18. Descriptive statistics were presented as mean, standard deviation, frequencies and percentage. The efficacy of etanercept was tested by comparing the mean of DAS28 in different times of evaluation. The ANOVA test was used to notice the change in the DAS28 mean with time (more than 2 means).In addition the paired t test was used to compare the change in DAS28 mean at baseline with DAS28 means at one month, three month and six month separately (comparing between two means only). Multiple logistic regression was used to assess the effect of patients characteristics (as predictors) on the response to treatment. The mean difference in DAS2 8 between baseline and 6 month was used as dependent variable to assess the correlation between these factors and the response to treatment. A level of significance ( $\mathrm{P}$ value) of $\leq 0.05$ is considered as significant, where as a level of significant of $\leq$ 0.001 is considered as highly significant.

\section{Results}

There were 190 patients enrolled in this prospective study with a mean age of $(47.43 \pm 11.9)$ and a range of $(20-95)$ years. Furthermore, the age distributed into two categories; 52 patients $(27.4 \%)$ were aged $\leq 40$ years and 138 patients $(72.6)$ were aged $>40$ years. Female patients were 158 (83.2\%). Smokers were 18 patients $(9.5 \%)$, RF was positive in 119 patients $(62.6 \%)$, and 162 patients $(85.3 \%)$ were taking MTX, Table 1.
Table1. Baseline characteristics of study group with rheumatoid arthritis. $(\mathrm{N}=190)$

\begin{tabular}{cccc}
\hline Variable & & No. & $\%$ \\
\hline \multirow{2}{*}{$\begin{array}{c}\text { Age } \\
\text { (years) }\end{array}$} & $\leq 40$ & 52 & 27.4 \\
\cline { 2 - 4 } Sex & $>40$ & 138 & 72.6 \\
\cline { 2 - 4 } & Male & 32 & 16.8 \\
\cline { 2 - 4 } Smoking & Female & 158 & $\mathbf{8 3 . 2}$ \\
\cline { 2 - 4 } & Nonoker & 18 & 9.5 \\
\hline \multirow{2}{*}{ Disease duration } & $<10$ years & 111 & 58.4 \\
\cline { 2 - 4 } & $\geq 10$ years & 79 & 41.6 \\
\hline \multirow{2}{*}{\begin{tabular}{c} 
Rheumatoid Factor \\
\cline { 2 - 4 }
\end{tabular}} & Positive & 119 & 62.6 \\
\cline { 2 - 4 } & Negative & 71 & 37.4 \\
\hline Concomitant \\
methotrexate use & Yes & 162 & 85.3 \\
\cline { 2 - 4 } & No & 28 & 14.7 \\
\hline
\end{tabular}

As shown in Table 2, the mean baseline of DAS28 was 5.98 \pm 1.02 and it was significantly reduced $(\mathrm{P}=0.009)$ at each time of evaluation to reach the lowest value $(4.23 \pm 1.12)$ after 6 months of evaluation.

The ANOVA test was highly significant on comparing the means of DAS28 in different times of evaluation. Furthermore, the Paired t test revealed a highly significant difference $(\mathrm{P}<0.001)$ between the baseline mean DAS28 vs. each other time of evaluation ( 1 month, 3 months and 6 months). These findings indicate the high efficacy of etanercept.

Table2. Comparison of mean DAS28at different evaluation time among study group of rheumatoid arthritis patients $(\mathbf{N}=190)$.

\begin{tabular}{|c|c|c|}
\hline Evaluation time & $\begin{array}{c}\text { DAS28 } \\
\text { Mean } \pm \text { SD }\end{array}$ & $\begin{array}{c}\text { Statistical } \\
\text { test and } \\
\text { P.value }\end{array}$ \\
\hline Baseline & $5.98 \pm 1.02$ & \multirow{4}{*}{$\begin{array}{l}\text { ANOVA test } \\
0.009 \text { [sig] }\end{array}$} \\
\hline After one month & $5.10 \pm 1.15$ & \\
\hline After three months & $4.65 \pm 1.14$ & \\
\hline After 6 months & $4.23 \pm 1.12$ & \\
\hline $\begin{array}{c}\text { Baseline vs. After one month } \\
\text { (difference) }\end{array}$ & $0.88 \pm 0.113$ & $\begin{array}{l}\text { Paired t test } \\
0.001 \quad[\text { sig] }\end{array}$ \\
\hline $\begin{array}{l}\text { Baseline vs. After three months } \\
\text { (difference) }\end{array}$ & $1.33 \pm 0.116$ & $\begin{array}{l}\text { Paired t test } \\
<0.001 \text { [sig] }\end{array}$ \\
\hline $\begin{array}{c}\text { Baseline vs. After } 6 \text { months } \\
\text { (difference) }\end{array}$ & $1.75 \pm 0.117$ & $\begin{array}{l}\text { Paired t test } \\
<0.001 \quad[\text { sig] }\end{array}$ \\
\hline
\end{tabular}


To assess the effect of patients' characteristics on response to treatment, multiple logistic regression analysis was conducted using 6 variables as predictors. These include the age, gender, diseases duration, the presence of RF, smoking status and the concomitant use of methotrexate. The mean difference in the DAS 28 between the baseline and last evaluation visit (6 months) was used as a dependent variable in the multiple logistic regression model. The analysis showed that gender has a significant correlation with response to treatment; with the females being more respondent to treatment than males( $\mathrm{P}=0.017)$. The concomitant use of methotrexate showed highly significant correlation with the treatment response ( $p$ $<0.001$ ) The other variables(including: age, disease duration, the presence of RF, and smoking) had no significant effect on response to treatment $(\mathrm{P}>0.05)$. The findings are shown in Table 3.

Table 3.The correlation between the rheumatoid arthritis patients characteristics and the response to treatment.

\begin{tabular}{|c|c|c|c|}
\hline \multirow[b]{2}{*}{ Variable } & \multicolumn{2}{|c|}{$\begin{array}{l}\text { Standardized } \\
\text { Coefficients }\end{array}$} & \multirow[b]{2}{*}{ P. } \\
\hline & $\begin{array}{c}\text { Correlation } \\
\text { coefficient }\end{array}$ & $\begin{array}{l}\text { Std. } \\
\text { Error }\end{array}$ & \\
\hline Age & 0.069 & 0.010 & 0.248 \\
\hline Gender/Female & -0.234 & 0.192 & 0.017 \\
\hline Disease Duration & 0.062 & 0.011 & 0.428 \\
\hline RF positive & $-0.097-$ & 0.161 & 0.19 \\
\hline Smoking & 0.033 & 0.295 & 0.674 \\
\hline $\begin{array}{c}\text { Concomitant } \\
\text { methotrexate use }\end{array}$ & -0.578 & 0.112 & 0.021 \\
\hline
\end{tabular}

Dependent Variable: Difference in mean DAS 28 ( baseline vs. 6 months)

The mean difference in DAS28 at baseline and 6 months was significant in both genders but it was highly significance in females (mean difference $=2.13, \mathrm{P}<0.001$ ) than the males (mean difference $=1.66, \mathrm{P}=0.013$ ) indicating that the response to etanercept is stronger among females than males. Figure 1.

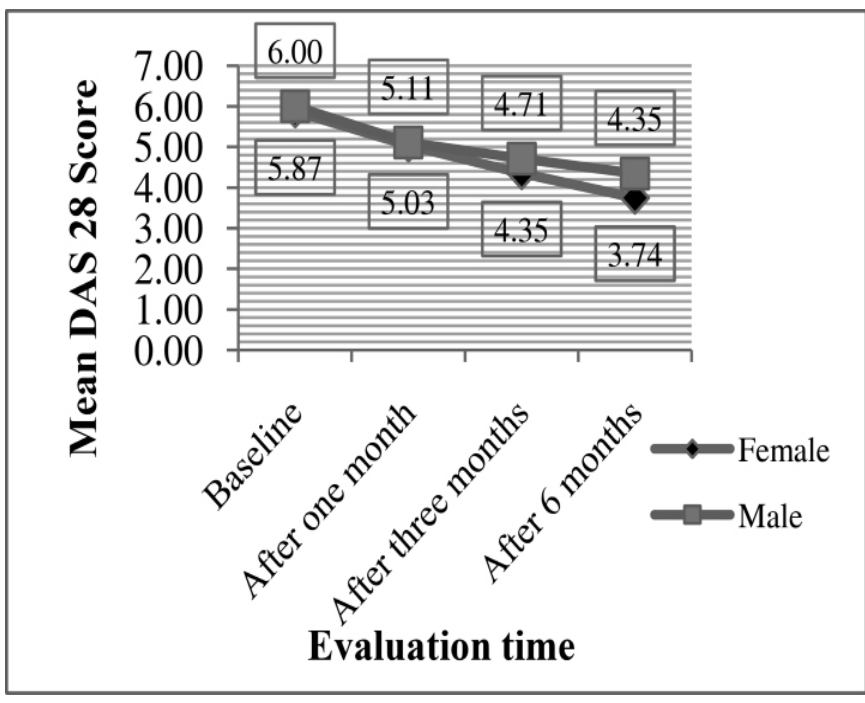

Figure 1. The changes in DAS 28 in patients with rheumatoid arthritis during the period of evaluation distributed by gender.

The mean difference in DAS28at baseline vs. 6 months was highly significant in MTX users group ( $\mathrm{P}<0.001)$, and it was not significant in nonusers $(\mathrm{P}=0.14)$. The mean difference was 1.86 vs. 1.11 respectively. Figure 2.

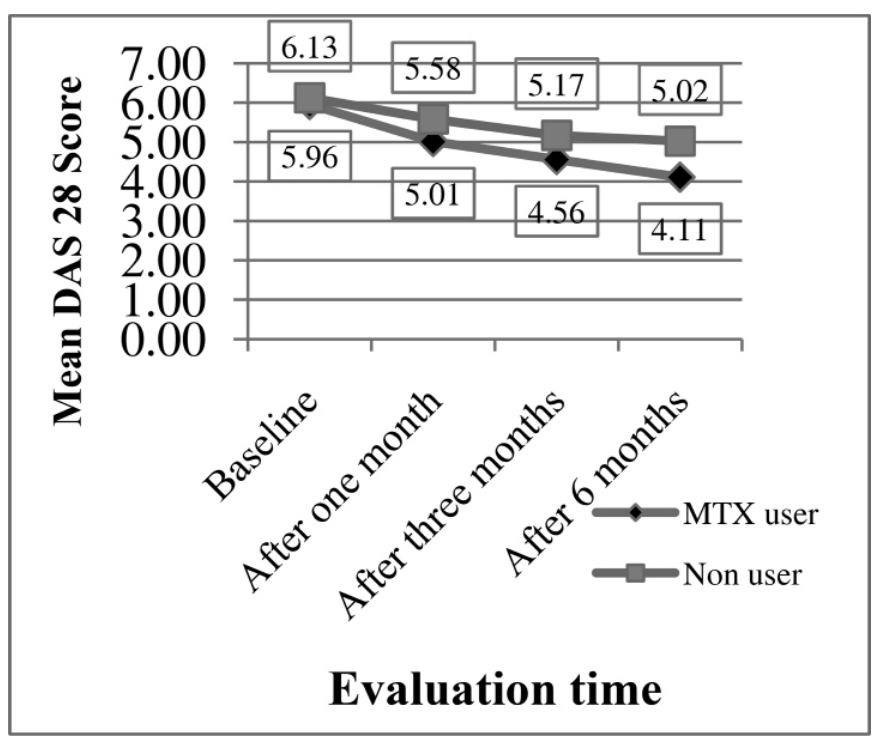

Figure 2. The changes in DAS 28 during the period of evaluation distributed by using methotrexate. MTX: Methotrexate 


\section{Discussion}

The immunogenicity against the biological agents is one of the most important factors predicting the response to treatment. Studies showed no immunogenicity(8) or insignificant immunogenicity(9) against etanercept treatment as compared to other TNF blockers. Therefore current studies are aiming to identify other predictor factors that can affect the response to etanercept treatment.

In this study we assessed the relationship between six patient characteristics (age, gender, disease duration, the presence of $\mathrm{RF}$, smoking status and the concomitant use of methotrexate) and the response to etanercept. There was significant correlation between concomitant use of methotrexate and the reduction in disease activity (DAS28) $(\mathrm{P}<0.021)$. Similar result was demonstrated by double-blind randomized control trials done by Emery P. et al (2008) and Kameda H. et al (2010) which found that the clinical remission and radiographic non-progression were highly significant in patients using combination therapy than those using etanercept monotherapy $(10,11)$. Our analysis showed no significant improvement in DAS28 in patients using etanercept as a monotherapy $(\mathrm{P}=0.14)$. This result was similar to study result conducted in Stockholm by Ronald F van et al(12). A possible explanation for the apparent superiority of concomitant use of methotrexate to predict response may be that methotrexate is a potent drug in itself, which has been proven in randomized placebo controlled trials(13). Another reason could be that patients tolerating methotrexate also possess yet undefined characteristics predisposing to good treatment responses, for which we were unable to adjust (14). Our analysis also showed that gender has a significant correlation with response to treatment with females being more respondent to treatment than males $(\mathrm{P}=0.017)$. A similar finding was observed by Anderson et al (15). However; different results were demonstrated by other studies. Karlsson et al(16). Showed that gender did not predict response to anti-TNF therapy while Atzeni et al (17) and Hyrich et al(18) showed that males have more significant correlation with response to etanercept. Straub et al.(19) have speculated that male patients should gain greater benefit from anti-TNF agents due to the effect of these medications on the neuro-endocrine axis, which result in higher levels of anti-inflammatory androgens in the synovial tissue of males as compared to females. Karlsson et al (16) and Hyrich et al(18) proved in their study the inverse association between the baseline DAS28 and chance of remission (defined as DAS28<2.6). Thus, it can be speculated that the predictive value of male sex found by Hyrich et al.(18) was to some degree confounded by the lower baseline scores of DAS28 in males, and on the contrary the predictive value of female sex found in our study might be influenced by the lower baseline scores of DAS28 in females. In addition, the differences found may also reflect genetic and/or environmental variations between RA patients in Iraq and in Europe. In this study, the patient's age, disease duration, presence of RF and smoking status have no significant effect on response to etanercept. Literature review revealed controversial evidence. An observational study carried out by Canhão et al (2012), they followed 617 patients with RA over one year and studied the effect of multiple predisposing factors on different TNF blockers(20). The study showed no significant association between age, disease duration and gender with response to treatment. However a significant negative correlation was found with the presence of RF and smoking. Hetland et al (21) in eight years of surveillance from Danish registry found that old age was a negative predictor of clinical response and remission. Gender and disease duration were not related to the treatment response. In a Atzeni et al cohorts observational study, the age, disease duration and presence of RF did not predict the response to TNF blockers(18). The difference in genetic backgrounds, population characteristics and analysis strategies may contribute to differences in results $(20,22)$. The choice of outcome measures may also influence the predictive value of treatment response $(16,17,20)$.

\section{Conclusion}

Female gender and concomitant use of methotrexate have a significant correlation with response to etanercept treatment in patients with RA.

\section{References}

1. Silman A, Klareskog L, Breedveld F, et al. Proposal to establish a register for the long term surveillance of adverse events in patients with rheumatic diseases exposed to biological agents: the EULAR Surveillance Register for Biological Compounds. Ann Rheum Dis 2000; 59(6):41920.

2. Lipsky PE. Rheumatoid arthritis. In: Fauci AS, Kasper $D L$, Longo DL, Braunwald E, Hauser SL, Jameson JL and Loscalzo J. Harrison's Rheumatology, 2nd Edn., New York, USA, The McGraw-Hill Companies, 2010, chapter 5: 82- 99.

3. Guidelines for Use of Biological Agents for Treatment of Rheumatic Diseases in Iraq. Prepared by Scientific Committee in Iraqi Society of Rheumatic Diseases. Endorsed by Iraqi Ministry of Health in November 2010.

4. Maini R, St ClairEW, BreedveldF, etal. Infliximab (chimeric anti-tumor necrosis factor alpha monoclonal antibody) versus placebo in rheumatoid arthritis patients receiving concomitant methotrexate: a randomized phase III trial. ATTRACT Study Group. Lancet 1999;354:1932-9.

5. Zink A, Listing JD, Kary Set al. Treatment continuation in patients receiving biologics or conventional DMARD Therapy. Ann Rheum Dis 2005;64:1274-9. 
6. Arnett FC, Edworthy SM, Bloch DA, et al. The American Rheumatism Association 1987 revised criteria for the classification of rheumatoid arthritis. Arthritis Rheum 1988;31(3):315-24.

7. Van Der Heijde DM, Van't Hof M, Van Riel PL, and Van De Putte LB. Development of a disease activity score based on judgment in clinical practice by rheumatologists. $J$ Rheumatol 1993;20: 579-81.

8. Mathews S, Schechtman J, Surbeck W, et al. The immunogenicity, safety, and efficacy of etanercept liquid administered once weekly in patients with rheumatoid arthritis. Clin Exp Rheumatol 2007;25:40-6.

9. de Vries MK, Nurmohamed MT, et al. Immunogenicity does not influence treatment with etanercept in patients with ankylosing spondylitis. Ann Rheum Dis 2009;68:531-5.

10. Emery P, Breedveld FC, et al. Comparison of methotrexate monotherapy with a combination of methotrexate and etanercept in active, early, moderate to severe rheumatoid arthritis (COMET): a randomised, double-blind, parallel treatment trial. Lancet 2008,2;372(9636):375-82.

11. Kameda H, Ueki Y, et al. Etanercept with methotrexate is better than etanercept monotherapy in patients with active rheumatoid arthritis despite methotrexate therapy: a randomized trial. Mod Rheumatol 2010;20(6):531-8.

12. Ronald FV, Sofia E, Anders H. et al. Etanercept Versus Etanercept Plus Methotrexate: A Registry-Based Study Suggesting that the Combination Is Clinically More Effacious. Arthritis Research \& Therapy 2003;(5) 6: R347-R51.

13. Klareskog L, van der Heijde D, de Jager JP, et al. (2004). Therapeutic effect of the combination of etanercept and methotrexate compared with each treatment alone in patientswithrheumatoidarthritis: doubleblindrandomised controlled trial. Lancet 2004,28;363(9410):675-81.

14. Kiely PDW and Johnson DM. Infliximab and leflunomide combination therapy in rheumatoid arthritis: an openlabel study. Rheumatology 2002;41:631-7.

15. Anderson JJ, Wells G, Verhoeven AC, et al. Factors predicting response to treatment in rheumatoid arthritis: the importance of disease duration. Arthritis Rheum 2000;43(1):22-9.

16. Karlsson JA, Kristensen LE, Kapetanovic MC, et al. Treatment response to a second or third TNF-inhibitor in RA: resultsfrom the South Swedish Arthritis Treatment Group Register. Rheumatology 2008;47:507-13.

17. Atzeni F, Bongiovanni S, Marchesoni A, et al. Predictors of response to anti-TNF therapy in $R A$ patients with moderate or high DAS28scores. Joint Bone Spine 2014;81(1):37-40.

18. Hyrich KL, Watson KD, Silman AJ and Symmons DPM. The BSR biologics Register. Predictors of response to
anti-TNF-alpha therapy among patients with rheumatoid arthritis: results from the British Society for Rheumatology Biologics Register. Rheumatology 2006;45:1558-65.

19. Straub RH, Harle P, Sarzi-Puttini P, et al. Tumor necrosis factor neutralizing therapies improve altered hormone axes: an alternative mode of anti-inflammatory action. Arthritis Rheum 2006;54:2039-46.

20. Canhão H, Rodrigues AM, Mourão AF et al. Comparative Effectiveness and Predictors of Response to Tumour Necrosis Factor Inhibitor Therapies in Rheumatoid Arthritis. Rheumatology 2012;51(11):2020-6. [IVSL, Oxford]

21. Hetland ML, Christensen IJ, Tarp U, et al. Direct comparison of treatment responses, remission rates, and drug adherence in patients with rheumatoid arthritis treated with adalimumab, etanercept, or infliximab: results from eight years of surveillance of clinical practice in the nationwide Danish DANBIO registry. Arthritis Rheum 2010;62:22-32. [IVSL, Wiley]

22. Tan R. and Barton A. Genetic predictors of response to anti-tumor necrosis factor drugs in rheumatoid arthritis. Rheumatology Reports 2009; 1:e1. [IVSL]. 